\title{
This old Mainframe
}

Anthony Pickert

Kansas City, Kansas

John Ciardi, in his How Does a Poem Mean?, says "Chess is a_play-activity, yet it is play only because the players deliberately make the game difficult in order to overcome the difficulties. The equation is simple: no difficulty, no fun. No chess player finds any real pleasure in playing an obviously inferior opponent. Every game ever invented by mankind is a way of making things hard for the fun of it. The great fun, of course, is in making the hard look easy."

Making the hard look easy is what I tried to do with the following poem. Many computer program words have other connotations in English. (Likewise, speech synthesis could use more consistent phonemes from spoken English.) Therefore, this verse is free. A mathematician in history recognized such difficulty of writing poems, because he was in both fields. He recognized that structure and creativity in both fields, however, should be equally easy.

Jacob Bronowski (1908-1974) was a world-class mathematician by training and a poet in his later years (among other roles). Much of his life was devoted to clarifying a relationship between art and science. For him, a poet must utilize imagination, as must a chess programmer or a creator of a math formula. His ideas are evident in the television series The Ascent of Man and a book called The Visionary Eye. The pamphlet I refer to in the poem is entitled Spain 1939: Four Poems (Andrew Marvel1 Press). (I used it to discuss Mr. Bronowski at a poetry meeting with a group called Collaborators.)

Mr. Bronowski is the man out of season who inspired me to make the trip to the University of Kansas and then to write this poem. For me, good programming is similar to good writing. Both must be efficient; both must be innovative and valuable. Both endeavors will aid each other.

Without a structure in programming that predicts enhancements, a compromise will require more programming around it than necessary. If a library set of books is not telecommunicated, then also a patron must run around. Frankly, I hope for the day when I can access a chess program or a library book via telecommunication. Then, once again, science aids itself and the arts. 


\section{This old Mainframe}

I bring myself 40 miles today to a library I had known well. Without computer I must find a poem. I have checked another library.

Into its frame I walk, and find a restructured chamber. A new signboard only could indicate where I must go.

"Nearness is convenience", I think as I go nearby to search for an index to a scientist difficult to find.

"What great news", I think as I see his 'Four Poems' card. I write the address code then push to fetch.

The walls exhibit no word like STACKS. I go upstairs to glance around. Russian stacks become my trial; I err.

I meander, wonder where the floor might be, or which end, at last. I slow for water.

"How could I be lost...", I ponder awhile,

"within these times of communication speed?"

I ask a scholarly someone. He shows me the proper port. I then pop for the book, reflecting within this old mainframe. 